\title{
Antioxidant and phenolic contents in potatoes (Solanum tuberosum L.) and micropropagated potatoes
}

\author{
Jinhee Kim"D, Soon Yil Soh², Haejin Bae ${ }^{1}$ and Sang-Yong Nam²*
}

\begin{abstract}
This work investigated the extraction efficacy of phenolic acids on the potato and its byproducts. Also, the compositions of bioactive compounds and antioxidants were evaluated in various parts of the potato, such as the tuber, microtuber, peel, and flesh. The chemical constituents were quantified by HPLC analysis, and the highest levels of phenolics $(88.99 \mathrm{mg} / \mathrm{L}$ ) were obtained in acetone extracts from a micropropagated potato. The micropropagated potato demonstrated that notable phenolic compounds were mainly a bound form of phenolic acids including caffeic acid and vanillic acid. The micropropagated extracts using acetone showed the higher radical scavenging activity, 94.3\% and $95.5 \%$ at $5 \mathrm{mg} / \mathrm{mL}$ in 1,1-diphenyl-2-picrylhydrazyl (DPPH) and 2,2'-azinobis-(3-ethylbenzothiazoline)-6-sulfonic acid $\left(\right.$ ABTS $\left.^{+}\right)$, respectively. In addition, the same extracts showed the highest $(85.61 \%) \beta$-carotene bleaching inhibition activity. A positive relationship existed between DPPH and either $\mathrm{ABTS}^{+}+(r=0.58, p<0.05), \beta$-carotene bleaching $(r=0.65, p<0.05)$, or total phenolics $(r=0.63, p<0.05)$. However, ABTS ${ }^{+}$did not show a significant correlation between both total phenolics and $\beta$-carotene bleaching. The effective phenolic compounds contributing to antioxidant activity were caffeic acid and vanillic acid, which could be extracted in high amounts by acetone from potato peels and micropropagated potatoes.
\end{abstract}

Keywords: $\beta$-Carotene bleaching, Microtuber, Phenolics, Potato, Radical scavenging

\section{Introduction}

The potato (Solanum tuberosum L.) is a root vegetable and one of the most widely consumed crops, followed by wheat and rice [1]. World potato production is estimated at about 400 million tons every year [2], and the value of production accounts for $\$ 3.7$ billion annually in the United States [3]. Indeed, potato production has great socioeconomic impacts in society. Currently, less than $50 \%$ of potatoes are consumed fresh; the rest are used for processed potato products, animal feed, and seed tubers for the next season's crops [4]. Also, the food processing industry benefits more from French fries and chips than fresh potatoes [1]. Potatoes supply key

\footnotetext{
*Correspondence: jhkimtamu@gmail.com; namsy@syu.ac.kr

${ }^{1}$ Division of Convergence Research, National Institute of Ecology, Seocheon, Republic of Korea

2 Department of Horticulture, Natural Science Research Institute,

Sahmyook University, Seoul, Republic of Korea
}

nutrients-potassium, fiber, protein, calcium, and magnesium - and are also known as a consolidated source of functional ingredients-vitamins B6, C, and E and various polyphenols and phenolic acids [5].

Previous research has investigated the agricultural and health benefits of potatoes and related implications, such as antibiotic, anticancer, and antioxidant properties [68]. In particular, the potato peel contains a rich source of phenolic compounds [9]. Although bioactive compounds are present in both the flesh and peel, the peels are largely discarded during potato consumption and processing. Therefore, more investigation of the utilization of potato byproducts or waste, like the peels, is warranted.

Traditionally, potatoes are propagated by cutting the vegetative tissue, which is tubers containing nodes or eyes $[10,11]$. Since the development of conventional techniques, such as tissue cultures, to obtain virus-free crops through mass propagation, micropropagated potatoes have been produced using tissue culture techniques 
$[10,12]$. In addition, by using tissue culture techniques, the propagated potato has more peel units per gram of powder due to its small size. Despite the socioeconomic importance of micropropagated potatoes as seeds, comparisons and phytochemical investigations of the seed potato's chemical constituents are scant. Indeed, the health benefits of the propagated microtubers have been rarely examined.

In this context, the present study aimed to analyze the composition of bioactive compounds in both potatoes and micropropagated potatoes (microtubers) as well as different parts of the potato through reversed-phase high-pressure liquid chromatography (HPLC). Using tissue cultures in vitro, the seed potatoes were micropropagated and the bioactive compositions were investigated. Moreover, the total phenolic contents, radical scavenging activity of potato extracts, and extraction efficacy were evaluated. Finally, the correlation between the total phenolic contents and their potential antioxidant content in extracts using (1,1-diphenyl-2-picrylhydrazyl [DPPH], 2,2'-azinobis-(3-ethylbenzothiazoline-6-sulfonic acid) [ABTS], and $\beta$-carotene bleaching assay) was assessed.

\section{Materials and methods Chemicals}

All solvents used in this study were analytical grade (Duksan Co., Seoul, ROK). Folin-Ciocalteu, sodium carbonate, DPPH, ABTS, and $\beta$-carotene were purchased from Sigma-Aldrich (St Louis, MO, USA). Gallic acid was obtained from Bio Basic Inc. (Ontario, Canada). Linoleic acid was supplied by Wako pure chemical (Dallas, TX, USA). DL- $\alpha$-tocopherol acetate $(\alpha-T A)$ was purchased from Daejung Chemicals (Siheung, ROK). Chlorogenic acid (purity $\geq 95 \%$ ), caffeic acid, vanillic acid, quercetin glucoside, and $p$-Coumaric acid were supplied by SigmaAldrich (St Louis, MO, USA).

\section{Plant materials}

Potato cultivars of type Sumi (Solanum tuberosum L. cv. Sumi), supplied by Innoseed Systems (Chungbuk, ROK), were harvested in 2013. Microtubers of cv. Sumi were generated using the nodal cutting technique in vitro. The explants were placed in a specialized container with liquid Murashige and Skoog (MS) medium supplemented with $8.5 \%$ sucrose and vitamin supplements. All the liquid medium was adjusted to $\mathrm{pH} 5.8$ and autoclaved at $121^{\circ} \mathrm{C}, 15 \mathrm{psi}$, for $15 \mathrm{~min}$. Stem segments $(2-2.5 \mathrm{~cm}$ long $)$ with many nodes were cultured into the liquid medium and incubated in a dark room at $20{ }^{\circ} \mathrm{C}$. After 8 weeks, eight microtubers $(0.2 \mathrm{~g}$ each) were obtained from each container (Fig. 1a).

\section{Preparation of potato extracts}

The Sumi tuber $(6.5 \mathrm{~kg})$ was washed with water, dried, and manually peeled to a depth of $\sim 1 \mathrm{~mm}$, and then the peel and the peeled potato (flesh) were blended separately with a commercial mixer. The tuber (unpeeled whole potato) and microtuber $(1 \mathrm{~kg})$ were washed with water and blended separately. The tuber, microtuber, peel, and flesh were dried and powdered using a freeze dryer (OPERON, ROK). Powdered potato (100 g) was added to $800 \mathrm{ml}$ of acetone, methanol, and a mixture of methanol:water $(80: 20, \mathrm{v} / \mathrm{v})$, respectively. After adding the solvent, the mixtures were shaken at $200 \mathrm{rpm}$ overnight, and the extracts were filtered through filter paper. The collected extracts were concentrated in a rotary evaporator to remove the major amounts of the organic solvents and were further dried in a freeze dryer.

\section{Chromatography conditions}

Phenolic compounds were quantified using an Ultimate 3000 HPLC system (Dionex, California, USA) with a UV/VIS diode array detector coupled with an auto sampler and a quaternary pump. The separation was carried out using an Agilent Zorbax SB-C18 column ( $250 \mathrm{~nm} \times 4.6 \mathrm{~mm}$ i.d. and $5 \mu \mathrm{m}$ particle size) at a flow rate of $0.8 \mathrm{~mL} / \mathrm{min}$. The gradient elution was obtained using (A) $0.3 \%$ trifluoroacetic acid, and (B) acetonitrile as follows: $10-60 \% \mathrm{~B}(0-25 \mathrm{~min}), 100 \% \mathrm{~B}$ (26-35 min), and $10 \% \mathrm{~B}(36-40 \mathrm{~min})$. The peaks were detected at $280 \mathrm{~nm}$, and data acquisition was completed with Dionex Chromeleon 6.8 version software. Calibration curves were constructed for five standard substances, and the correlation coefficients of the calibration curves were found to be significant at $p<0.01$. The structures of the standard compounds are presented in Fig. $1 \mathrm{~b}$.

\section{Determination of total phenolic contents}

The total phenolic contents in each extract were determined using a Folin-Ciocalteu reagent, according to a previously published procedure [13]. In brief, gallic acid (as a standard phenolic compound) and $100 \mu \mathrm{l}$ of each extract were distributed in the test tube and mixed with $500 \mu \mathrm{l}$ of the diluted Folin-Ciocalteu (1:1 ratio in distilled water). After a $10 \mathrm{~min}$ incubation at room temperature, $1 \mathrm{ml}$ of sodium carbonate $(7.5 \% \mathrm{w} / \mathrm{v})$ was mixed in the same tube and allowed to react for $20 \mathrm{~min}$ at room temperature. The absorbance of the mixture was measured at $760 \mathrm{~nm}$ and calculated the percentage of phenolics. The content of total phenolics was expressed as gallic acid equivalent (GAE). 
a

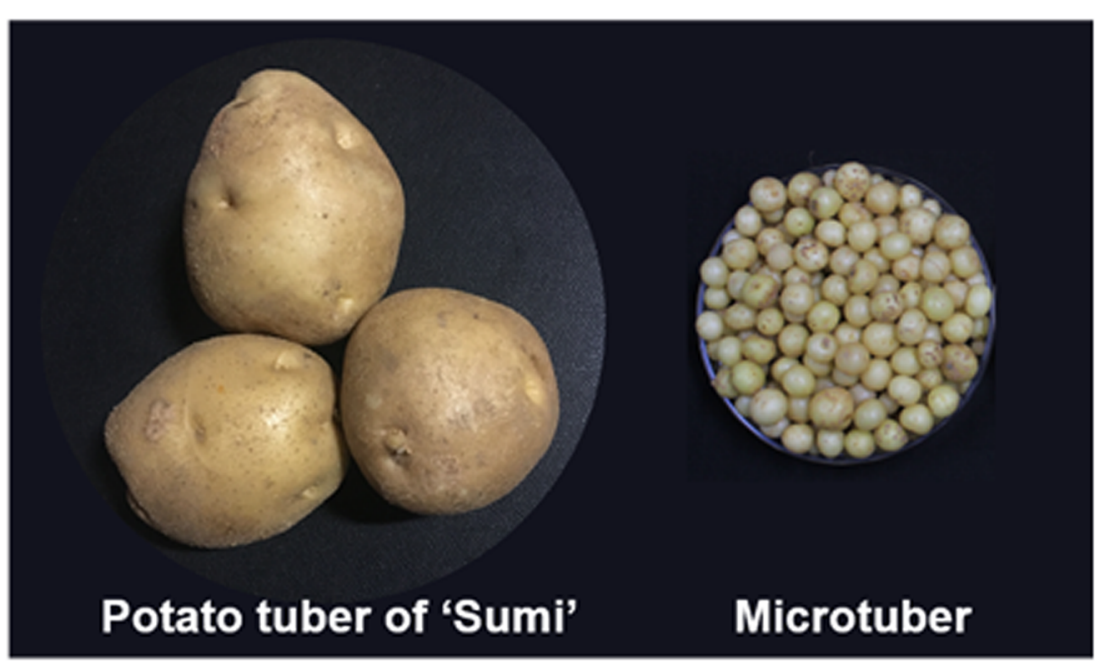<smiles>O=C(/C=C/c1ccc(O)c(O)c1)O[C@@H]1C[C@@](O)(C(=O)O)C[C@H](O)[C@H]1O</smiles><smiles>O=C(O)/C=C/c1ccc(O)c(O)c1</smiles>

\section{Chlorogenic acid}<smiles>O=c1c(OC2OC(O)[C@@H](O)C(O)[C@H]2O)c(-c2ccc(O)c(O)c2)oc2cc(O)cc(O)c12</smiles>

\section{Quercetin-3-glucoside}<smiles>O=C(O)/C=C/c1ccc(O)cc1</smiles>

p-Coumaric acid<smiles>COc1cc(C(=O)O)ccc1O</smiles>

Fig. 1 a Sumi potato cultivar tuber and its micropropagated tuber (microtuber) using the tissue culture technique. $\mathbf{b}$ The structures of the tested phenolic compounds from the potato

DPPH radical scavenging activity

A DPPH radical solution $(0.1 \mathrm{mM})$ was prepared with $38.35 \mathrm{mg}$ of DPPH dissolved in $1000 \mathrm{ml}$ of $\mathrm{MeOH}$. Two different concentrations ( 2.5 and $5.0 \mathrm{mg} / \mathrm{mL}$ ) of sample extracts and gallic acid as a control were presented into a 96-well plate and adjusted with $\mathrm{MeOH}$ to make $40 \mu \mathrm{l}$ 
of final volume. Two hundred microliters of DPPH solution was then added into and monitored for $33 \mathrm{~min}$ by absorbance at $518 \mathrm{~nm}$ using a FLUOstar Optima microplate reader (BMG Labtech, Durham, NC, USA).

\section{ABTS radical scavenging activity}

ABTS was dissolved in water to a $7 \mathrm{mM}$ concentration, and $2.45 \mathrm{mM}$ potassium persulfate was prepared. Two stock solutions were mixed and kept in the dark at room temperature for $16 \mathrm{~h}$ before use. The ABTS solution was diluted with methanol to an absorbance of 0.700 at $734 \mathrm{~nm}$ and equilibrated at $30{ }^{\circ} \mathrm{C}$. After the addition of $200 \mu \mathrm{l}$ of the diluted ABTS solution to $40 \mu \mathrm{l}$ of the sample extracts ( 2.5 and $5.0 \mathrm{mg} / \mathrm{mL}$ concentration), the decrease in absorbance was measured for 1 min after mixing the solution, and the final absorbance reading was monitored for $33 \mathrm{~min}$ by absorbance at $734 \mathrm{~nm}$ using a FLUOstar Optima microplate reader (BMG Labtech, Durham, NC, USA).

\section{$\beta$-Carotene bleaching activity}

The current $\beta$-carotene bleaching activity was determined using a modification of the method described by Marco [14]. In this method, $5 \mathrm{mg} \beta$-carotene, $20 \mu \mathrm{l}$ of linoleic acid, and $100 \mu \mathrm{l}$ of Tween 20 were dissolved in $10 \mathrm{ml}$ of chloroform in a round-bottom flask. After removing the chloroform, $10 \mathrm{ml}$ of distilled water was added and stirred vigorously for $10 \mathrm{~min}$. Thereafter, $240 \mu \mathrm{l}$ of the emulsion was placed with $10 \mu \mathrm{l}$ of extracts at various concentrations $(1,2,3,4$, and $5 \mathrm{mg} / \mathrm{mL})$ or butylated hydroxytoluene (BHT) as a positive control on 96-well plates. The absorbance was measured every $15 \mathrm{~min}$ for $120 \mathrm{~min}$ using the FLUOstar Optima microplate reader at $470 \mathrm{~nm}$. The antioxidant activity of extracts in terms of $\beta$-carotene bleaching was calculated using the following formula: AA $\%=\left[1-\left(\mathrm{Abs}_{0}\right.\right.$ sample $-\mathrm{Abs}_{120}$ sample $) /\left(\mathrm{Abs}_{0}\right.$ control $-\mathrm{Abs}_{120}$ control)] $\times 100$.

\section{Statistical analysis}

was conducted using Microsoft Excel and SPSS 19.0 for Windows (Chicago, IL, USA). A one-way and a two-way analysis of variance (ANOVA) followed by the Tukey post hoc test were used to analyze statistical significance $(p<0.05)$. The Spearman correlation coefficient was applied to evaluate the degree of correlation between the different antioxidant activity categories, DPPH, ABTS, total phenolics, and beta-carotene bleaching. The analysis was carried out at least in triplicate. Significance and confidence level were estimated at $p<0.05$.

\section{Results and discussion}

Total phenolic content and phenolic composition

Phenolics, which are well-known and important phytochemicals, are widely distributed in the plant kingdom, and variation in their chemicals occurs through different biosynthesis and chemical reactions such as hydroxylation, glycosylation, form of esters, and glycosides [15, 16]. Therefore, over the last 50 years, numerous research studies have focused on finding optimum extraction and identification techniques to obtain higher amounts of phenolic compounds from a source [17]. Phenolic compounds are secondary plant metabolites, and the most abundant phenolic acids, primarily chlorogenic acid, constitute up to $90 \%$ of the total phenolic compounds in potatoes [9]. For the current study, the total phenolic contents present in different extracts from various parts of the potato, such as the tuber, microtuber, flesh, and peel, are shown in Table 1. The amount of total phenolic

Table 1 Total phenolic content of respective extracts from different parts of the potato (tuber, flesh, and peel) and micropropagated potato tuber

\begin{tabular}{|c|c|c|c|}
\hline \multirow[t]{2}{*}{ Samples } & \multicolumn{3}{|c|}{ Total phenolics (mg GAE per g of extract) } \\
\hline & Acetone & Methanol & $80 \%$ Methanol \\
\hline Tuber & $28.89 \pm 0.28 \mathrm{aA}$ & $29.93 \pm 1.28 \mathrm{aA}$ & $39.02 \pm 2.96 \mathrm{bA}$ \\
\hline Microtuber & $63.17 \pm 4.59 \mathrm{aB}$ & $73.87 \pm 7.74 \mathrm{bB}$ & $44.80 \pm 4.26 \mathrm{CB}$ \\
\hline Flesh & $22.83 \pm 0.43 \mathrm{aC}$ & $28.58 \pm 1.32 \mathrm{aA}$ & $27.74 \pm 1.28 \mathrm{aC}$ \\
\hline Peel & $38.99 \pm 5.55 \mathrm{aD}$ & $29.24 \pm 1.63 \mathrm{bA}$ & $24.08 \pm 0.66 \mathrm{bc}$ \\
\hline \multirow[t]{2}{*}{ Source } & \multicolumn{3}{|c|}{ Two-way ANOVA analysis } \\
\hline & df & $\mathbf{F}$ & $p$ \\
\hline Solvent & 2 & 10.895 & $<0.001$ \\
\hline Part of potato & 3 & 177.989 & $<0.001$ \\
\hline Solvent part of potato & 6 & 22.022 & $<0.001$ \\
\hline
\end{tabular}

Values represented as mean \pm standard deviation in triplicate analysis. The values with lowercase letters (a-c) and capital letters (A-D) are significantly different in rows and columns, respectively, for the one-way ANOVA followed by Tukey post hoc test $(p<0.05)$ 
content in various parts of the potato ranged from 79.14 to $181.85 \mathrm{mg}$ GAE per gram of extract. The amount of total phenolic content was high in the microtuber and low in the potato flesh. The highest extraction yields of total phenolics in the microtuber, tuber, and peel were obtained using methanol, $80 \%$ methanol, and acetone, respectively. In the case of the flesh of the potato, extraction efficiency was not determined (Table 1). In order to understand the interaction between the extraction solvent and the part of the potato affecting total phenolic content extraction efficacy, a two-way ANOVA was conducted. Tukey post hoc analysis indicated $80 \%$ methanol was significantly different with both acetone $(p=0.01)$ and methanol $(p=0.00)$. In the Tukey test, acetone-methanol did not show any significant differences $(p=0.38)$. In the analysis of the part of the potato, while the flesh-peel $(p=0.06)$ and peel-tuber $(p=0.68)$ were not significant, other parts of the potato indicated significant differences for total phenolic contents at $p<0.01$. This study showed the extraction efficiency by using the different extraction solutions, although many other studies focused on the various cultivars of potatoes to find total phenolics [1820]. Our results indicate that the extraction efficiency of the extraction solutions varied in the tuber, microtuber, flesh, and peel of the potato.

In order to compare the phenolic composition in different extractions from the tuber, microtuber, flesh, and peel of the potato, phenolic acids and glucoside were identified and quantified (Table 2). Chlorogenic acid, caffeic acid, vanillic acid, quercetin glucoside, and $p$-coumaric acid were quantified using HPLC because total phenolic contents measured by the Folin-Ciocalteu procedure did not show any specification of phenolic composition. Calibration curves were obtained using the equations for chlorogenic acid, caffeic acid, vanillic acid, quercetin glucoside, and $p$-coumaric acid, respectively: $y=0.9994 x+0.0441 \quad\left(r^{2}=0.9998\right)$, $\mathrm{y}=0.9987 \mathrm{x}+0.0977\left(\mathrm{r}^{2}=0.9997\right), \mathrm{y}=0.9995 \mathrm{x}+0.0363$ $\left(r^{2}=0.9999\right), \quad y=0.9992 x+0.0621 \quad\left(r^{2}=0.999\right)$, $y=0.9985 x+0.1162\left(r^{2}=0.9995\right)$. Phenolic acids were found to be major phenolic compounds (Table 2), and these observations are in agreement with previous studies by Akyol et al. [9] and Zhu et al. [21]. In our results, vanillic acid, followed by caffeic acid, was identified as the predominant phenolic acid in potatoes (Table 2). However, several other authors have found chlorogenic acid to be the most abundant phenolic acid in potatoes [9, 22, 23]. Zhu et al. [21] quantified higher amounts of vanillic acid and caffeic acid than chlorogenic acid and attributed the finding to the high-pressure homogenization extraction method. Since the vanillic acid and caffeic acids are free forms of phenolic acid, which differ from chlorogenic acid, which is a bound form [24], in our extraction procedure, the blending process could apparently improve the yield of the non-bound form of the phenolic acid content.

Table 2 Quantification of the phenolic chemical composition in different parts of the potato (tuber, flesh, and peel) and micropropagated potato tuber

\begin{tabular}{|c|c|c|c|c|c|c|}
\hline \multirow[t]{2}{*}{ Extract } & \multicolumn{5}{|c|}{ Phenolic compounds } & \multirow[t]{2}{*}{ Total (mg/L) } \\
\hline & Chlorogenic acid & Caffeic acid & Vanillic acid & Quercetin glucoside & p-Coumaric acid & \\
\hline \multicolumn{7}{|l|}{ Tuber } \\
\hline Acetone & $0.15 \pm 0.00^{\mathrm{a}}$ & $2.30 \pm 0.01^{\mathrm{a}}$ & $3.03 \pm 0.09^{\mathrm{a}}$ & - & $0.08 \pm 0.01^{\mathrm{a}}$ & $5.55 \pm 0.11$ \\
\hline Methanol & $1.47 \pm 0.10^{b}$ & $1.40 \pm 0.04^{b}$ & - & $1.26 \pm 0.08^{\mathrm{a}}$ & - & $4.13 \pm 0.22$ \\
\hline $80 \%$ Methanol & $1.16 \pm 0.06^{c}$ & $0.85 \pm 0.05^{c}$ & - & - & - & $2.47 \pm 0.11$ \\
\hline \multicolumn{7}{|l|}{ Microtuber } \\
\hline Acetone & - & $47.81 \pm 0.81^{d}$ & $40.33 \pm 1.36^{b}$ & - & $0.85 \pm 0.03^{b}$ & $88.99 \pm 2.20$ \\
\hline Methanol & $1.17 \pm 0.06^{d}$ & $17.28 \pm 0.27^{e}$ & $27.30 \pm 0.46^{c}$ & - & $0.33 \pm 0.01^{c}$ & $46.07 \pm 0.80$ \\
\hline $80 \%$ Methanol & $1.20 \pm 0.04^{e}$ & $10.81 \pm 0.08^{f}$ & $23.30 \pm 0.46^{d}$ & - & $0.16 \pm 0.02^{d}$ & $35.47 \pm 0.61$ \\
\hline \multicolumn{7}{|l|}{ Flesh } \\
\hline Acetone & - & $0.21 \pm 0.00^{\mathrm{g}}$ & $2.68 \pm 0.12^{\mathrm{a}}$ & - & - & $2.89 \pm 0.12$ \\
\hline Methanol & $0.87 \pm 0.00^{f}$ & - & - & - & - & $0.87 \pm 0.00$ \\
\hline $80 \%$ Methanol & $1.00 \pm 0.02^{\mathrm{g}}$ & - & - & - & - & $1.00 \pm 0.02$ \\
\hline \multicolumn{7}{|l|}{ Peel } \\
\hline Acetone & $0.43 \pm 0.01^{h}$ & $15.44 \pm 0.24^{h}$ & $6.57 \pm 0.09^{e}$ & - & $0.06 \pm 0.00^{\mathrm{a}}$ & $22.51 \pm 0.34$ \\
\hline Methanol & $3.25 \pm 0.11^{i}$ & $6.53 \pm 0.01^{i}$ & $8.87 \pm 0.22^{f}$ & - & - & $18.66 \pm 0.34$ \\
\hline $80 \%$ Methanol & $1.98 \pm 0.06^{j}$ & $1.78 \pm 0.01^{j}$ & $3.72 \pm 0.08^{g}$ & - & - & $7.49 \pm 0.15$ \\
\hline
\end{tabular}

Data are expressed as mean \pm standard deviation of triplicate analysis. Values marked with different letters are significantly different for the two-way ANOVA followed by Tukey post hoc test at $p<0.05$ 
Several authors have studied the optimization of the extraction method or food processing method that improves the health effects related to having antioxidants [23]. In this present study, in comparing the three extraction solutions, acetone extract showed the highest efficiency in all the tested potato extracts. Although vanillic acid (tuber-flesh) and $p$-coumaric acid (tuberpeel) in the acetone extract did not show significant differences, all other separate compounds were significantly different in a two-way ANOVA test. In addition, the total amounts of five compounds were significantly different in all the tested extraction solvents and parts of the potato at $p<0.01$. Among the different parts of the potato, the microtuber contained the highest amount of phenolic compounds in acetone $(88.99 \mathrm{mg} / \mathrm{L})$, methanol $(46.07 \mathrm{mg} / \mathrm{L})$, and $80 \%$ methanol $(35.47 \mathrm{mg} / \mathrm{L})$ extraction solvents. Peel extracts ranked second in terms of phenolic compounds in acetone $(22.51 \mathrm{mg} / \mathrm{L})$, methanol $(18.66 \mathrm{mg} / \mathrm{L})$, and $80 \%$ methanol $(7.49 \mathrm{mg} / \mathrm{L})$. Flesh exhibited the lowest efficacy in all tested extracts. These results are in agreement with previous research findings that potato peels have the highest amount of phenolic compounds and flavonoids [25]. A study comparing major flavonoids and phenolic acid in the different parts (tuber, leaves, and flower) using 26 cultivars of Solanum tuberosum L. noted that the tuber (peel and flesh) contains a high percentage of total phenolic acid and relatively low flavonoids-about $79 \%$ and $9 \%$, respectively [26]. By contrast, leaves contain about $36 \%$ and $64 \%$ of phenolic acid and flavonoids, respectively [26]. It should be noted that the phenolic acid pathway along with phenolic precursor compounds, rather than the flavonoid pathway, has been largely linked to the major phenolic acid in both the peel and flesh [26].

\section{Radical scavenging activity}

Reactive oxygen species, produced as a byproduct of metabolic reactions, are widely intercorrelated in biological system controlling processes such as growth, regulation of environmental stress, development, and defense mechanisms [27]. Due to the toxicity of these reactive molecules, the ameliorative effect of radical scavengers has become a targeted research area related to disease prevention. Indeed, potatoes have been nominated as a better source of phenolic compounds-as antioxidantsthan other vegetables and fruits, such as carrots, onions, and tomatoes, due to their higher daily consumption [28]. Using the DPPH and ABTS radicals, which are the most popular radicals for measuring antioxidant activity [29], we measured the radical scavenging activity in different extracts from various potato parts, including the tuber, microtuber, flesh, and peel. In the comparison of the flesh and peel, the peel had higher antioxidant scavenging activities in the extract solution (Fig. 2b, d). Antioxidant activities using DPPH and ABTS were higher in acetone extracts, in which DPPH and ABTS were $97.9 \%$ and $96.6 \%$ at $5 \mathrm{mg} / \mathrm{mL}$, respectively. DPPH and ABTS at $2.5 \mathrm{mg} / \mathrm{mL}$ were also higher in acetone extracts in potato peels. However, DPPH and ABTS radical scavenging activities were variable in the extraction solutions of the potato peel. The comparison of the antioxidant activity in the potato tuber and microtuber showed that the microtuber had higher DPPH and ABTS radical scavenging activities than the tuber (Fig. 2a, c). When comparing the potato extracts at the $5 \mathrm{mg} / \mathrm{mL}$ concentration, the acetone extraction of the microtuber exhibited high antioxidant capacity by DPPH (94.3\%) and ABTS (95.5\%) assay, while the tuber showed minimum radical scavenging activities by DPPH (13.7\%) and ABTS (18.2\%) at $5 \mathrm{mg} / \mathrm{mL}$ of acetone extract. These results showed that the most potent antioxidant activities were found in acetone extracts of the potato microtuber and peel, while the least antioxidant activities were observed in acetone extracts of the potato flesh and tuber. A number of studies investigated the higher antioxidant activity in potato peels, which contain $90 \%$ of phenolic compounds, versus the whole potato or flesh [9]. Similarly, our data showed that peels have higher antioxidants than the whole potato tuber and flesh.

Interestingly, microtubers showed the highest antioxidant activity in all the tested solvent extracts (acetone, methanol, $80 \%$ methanol) (Fig. 2), with consistent amounts of total phenolic contents and phenolic compounds (Tables 1, 2). It seems that the antioxidant capacity is greatly influenced by not only the extraction solution but also the potato part (tuber, microtuber, flesh, and peel). Also, these data clearly support the idea that the phenolic compounds act as antioxidants.

Even though microtuber chemical constituents have not yet been studied much, as previously reported for the phenolic contents in potatoes, the tuber peel is considered the predominant source for phenolic acid, rather than any other parts of the potato, such as the flesh, leaves, or flower $[9,26]$. As noted previously, the microtuber has more peel units per gram of powder due to its small size; thus, our results are consistent with the literature in supporting the role of potato peels as a good source of bioactive compounds. A recent paper by Navarre et al. demonstrated that phenolic concentration is much higher in immature tubers than mature tubers, and is responsible for the increased phenylpropanoid content contributed by the high content of sugar in immature tubers [30]. The maturation difference between the micropropagated tuber and potato (peel, flesh) controls the phenylpropanoid biosynthesis via the acting sugar contents; therefore, the micropropagated potato tuber, 

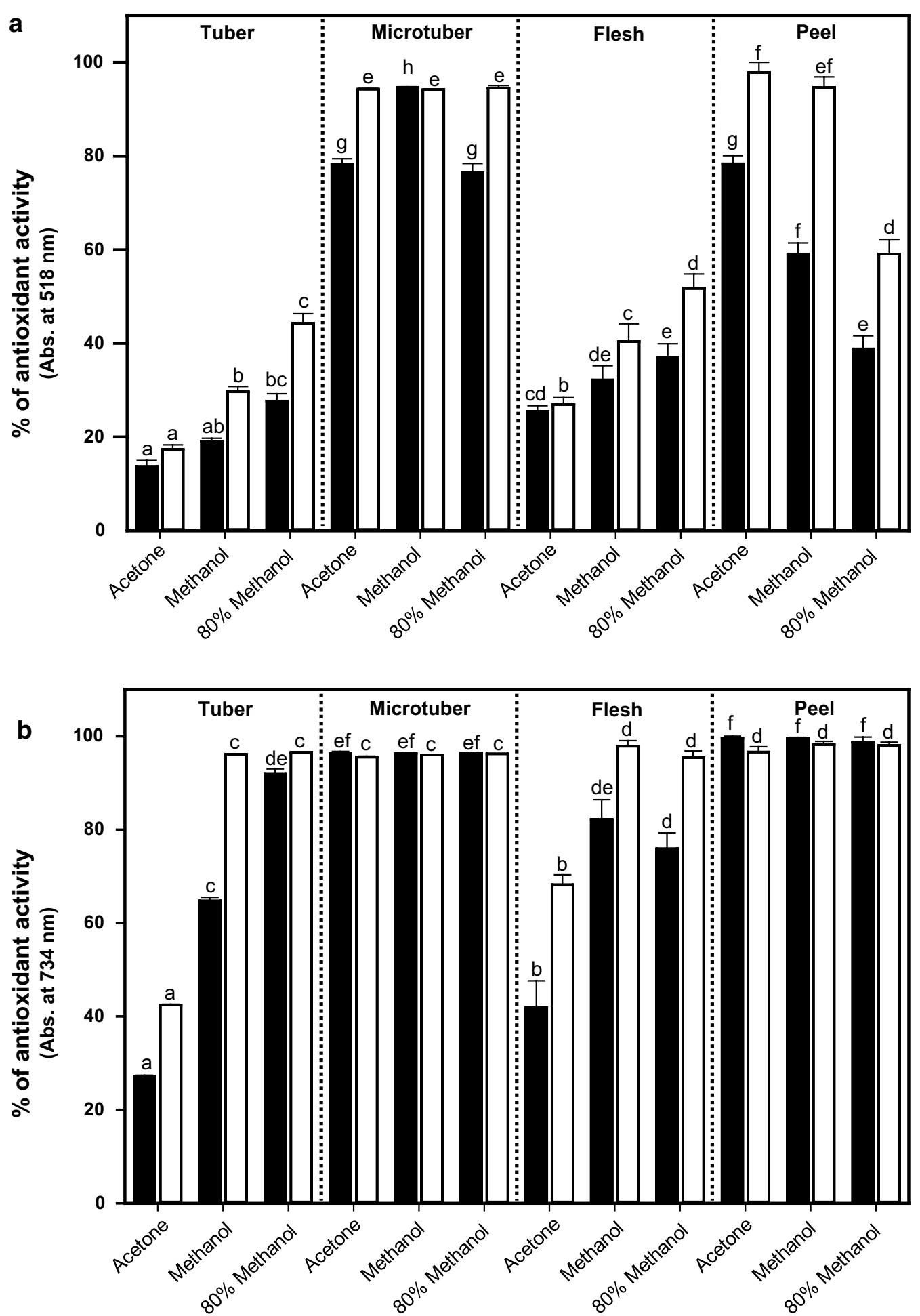

Fig. 2 a DPPH; and $\mathbf{b}$ ABTS free radical scavenging activity of the various solvent extracts from the tuber, microtuber, flesh, and peel of the potato at $2.5 \mathrm{mg} / \mathrm{mL}$ (black bar) and $5 \mathrm{mg} / \mathrm{mL}$ (white bar). The different lowercase letters indicate significant differences in all series of extracts at 2.5 and $5 \mathrm{mg} / \mathrm{mL}$, respectively. One-way ANOVA followed by Tukey post hoc test was performed to analyze statistical significance $(p<0.05)$ 

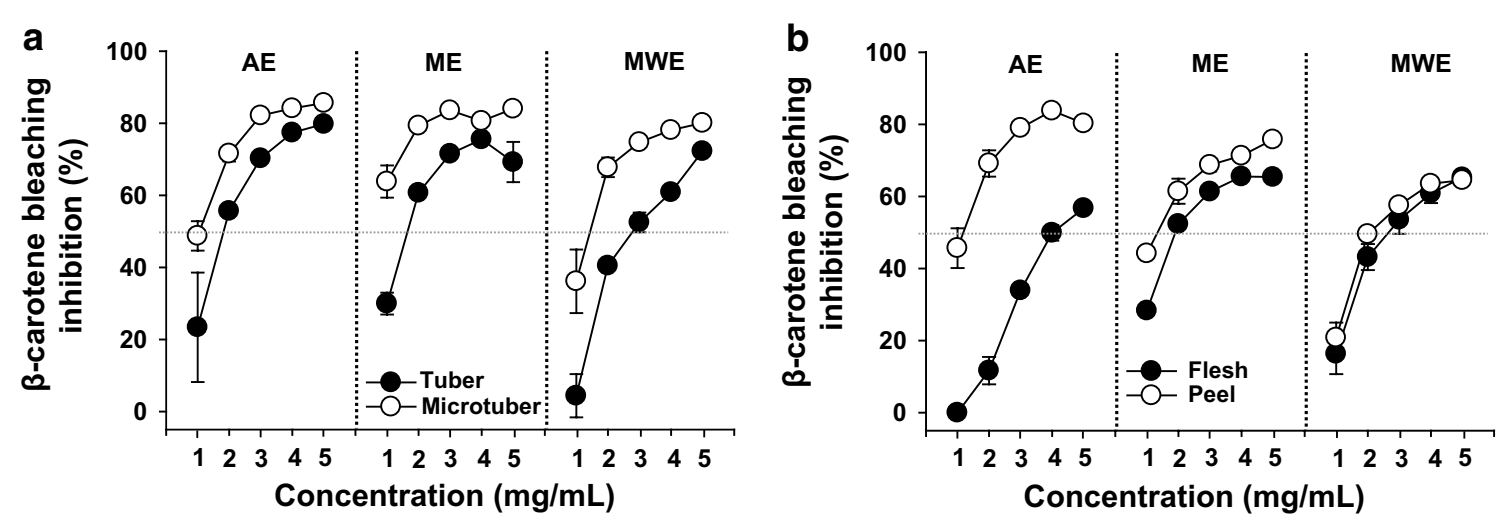

Fig. 3 -Carotene bleaching activity was determined in different solvent extracts from the potato: a tuber and microtuber extracts, $\mathbf{b}$ flesh and peel extracts. The bars represent standard deviations of three independent experiments. The significance and confidence levels were estimated using one-way ANOVA $(p<0.05)$. AE acetone extract, ME methanol extract, MWE $80 \%$ methanol in water extract
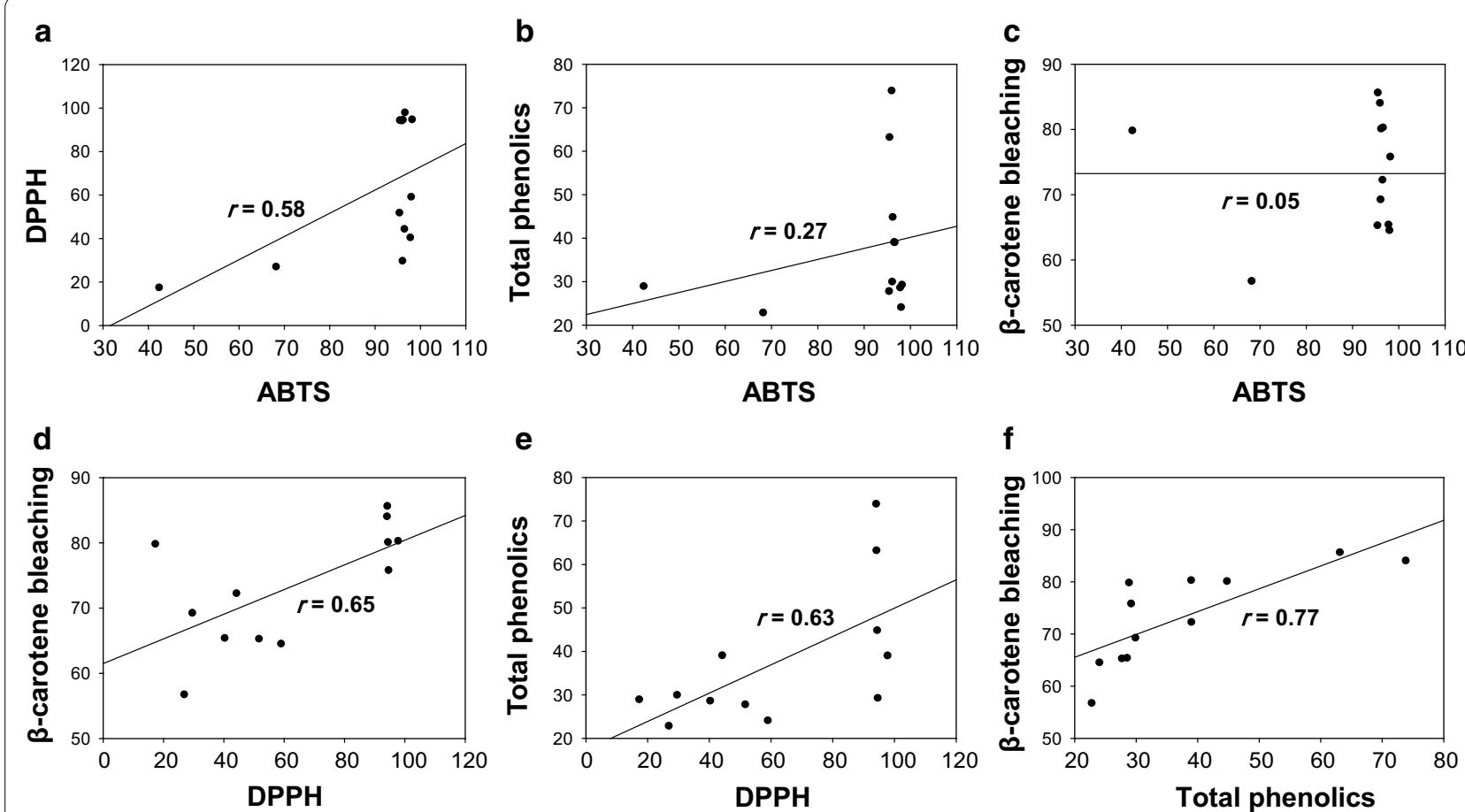

Fig. 4 Scatterplot of the interaction between the different methods to measure antioxidant activity. The correlation was determined by the Spearman coefficient of correlation method. Correlation coefficient between ABTS and either a DPPH $(r=0.58, p<0.05)$ or $\mathbf{b}$ total phenolics $(r=0.27, p>0.05)$. Correlation coefficient between $\beta$-carotene bleaching and either c ABTS $(r=0.05, p>0.05)$ or $\mathbf{d}$ DPPH $(r=0.65, p<0.05)$.

Correlation coefficient between total phenolics and either $\mathbf{e}$ DPPH $(r=0.63, p<0.05)$ or $\mathbf{f} \beta$-carotene bleaching $(r=0.77, p<0.05)$

which is an immature tuber, contains the highest antioxidant activity reflecting phenolic contents [30, 31]. However, it is not clear whether the highest antioxidant potential is due to the contribution of the peel or immaturation. This maturation effect should be taken into consideration in future studies seeking to find the maximum extraction efficacy using optimized extraction of bioactive compounds in potato tubers.

\section{$\beta$-Carotene bleaching inhibition}

The antioxidant activities of potato parts using the $\beta$-carotene bleaching assay were evaluated by measuring the inhibition of potato extracts (Fig. 3). $\beta$-Carotene bleaching inhibition showed that maximum antioxidant activity was observed in the potato microtuber followed by the peel, tuber, and flesh. The order of antioxidant activity of the potato microtuber, peel, flesh, and tuber 
was similar to the DPPH and ABTS radical scavenging activity. It was also clear that acetone extracts of most potato parts highly inhibited antioxidant activity compared to ME and MWE extracts.

\section{Correlation coefficients between the total phenolic content and antioxidant activities}

The Spearman correlation between the total phenolic content, radical scavenging activities, and bleaching activity was evaluated and is presented in Fig. 4. The correlation coefficient of the DPPH radial scavenging activity showed a significantly positive correlation with ABTS $(r=0.58, p<0.05)$ (Fig. 4a), $\beta$-carotene bleaching $(r=0.65, p<0.05)$ (Fig. $4 \mathrm{~d})$, and total phenolics $(r=0.63$, $p<0.05$ ) (Fig. 4e). Similarly, the total phenolic content was also significantly correlated to $\beta$-carotene bleaching $(r=0.77)$ (Fig. 4f). However, the level of ABTS was not correlated to total phenolics and inhibition of $\beta$-carotene bleaching (Fig. 4b, c).

\section{Authors' contributions}

JK analyzed the data and wrote the paper. SYS provided technical assistance to JK and helped with the data collection. HB edited the manuscript. SN supervised the work. JK revised and edited the manuscript and supervised the work. All authors read and approved the final manuscript.

\begin{abstract}
Acknowledgements
Financial support, in part, by Sahmyook University and National Institute of Ecology (NIE-C-2019-13) are gratefully acknowledged. The authors thank Chang Ho Soh for providing the micropropagated potato.
\end{abstract}

\section{Competing interests}

The authors declare that they have no competing interests.

\section{Publisher's Note}

Springer Nature remains neutral with regard to jurisdictional claims in published maps and institutional affiliations.

Received: 26 October 2018 Accepted: 12 March 2019

Published online: 22 March 2019

\section{References}

1. Schieber A, Saldaña MDA (2009) Potato peels: a source of nutritionally and pharmacologically interesting compounds-a review. Food 3:23-29

2. STAT F (2017) Food and agriculture organization statistical database. http://faostat.fao.org/. Accessed 27 Feb 2017

3. NASS U (2016) Agricultural statistics. Annual. https://www.nass.usda.gov/ Publications/Ag_Statistics. Accessed 2016

4. FAO (2008) Food and agricultural organization. I International year of the potato: the potato cultivation. http://www.potato2008.org @FAO,2008

5. Zaheer K, Akhtar MH (2016) Potato production, usage, and nutrition-a review. Crit Rev Food Sci Nutr 56:711-721

6. Roleira FM, Tavares-da-Silva EJ, Varela CL, Costa SC, Silva T, Garrido J, Borges F (2015) Plant derived and dietary phenolic antioxidants: anticancer properties. Food Chem 183:235-258
7. Shahidi F, Ambigaipalan P (2015) Phenolics and polyphenolics in foods, beverages and spices: antioxidant activity and health effects - a review. J Funct Foods 18:820-897

8. Brown C (2005) Antioxidants in potato. Am J Potato Res 82:163-172

9. Akyol H, Riciputi Y, Capanoglu E, Caboni MF, Verardo V (2016) Phenolic compounds in the potato and its byproducts: an overview. Int J Mol 17:835

10. Hoque M (2010) 'In vitro' tuberization in potato ('Solanum tuberosum'L.). Plant Omics 3:7

11. Donnelly DJ, Coleman WK, Coleman SE (2003) Potato microtuber production and performance: a review. Am J Potato Res 80:103-115

12. Mohapatra PP, Batra V (2017) Tissue culture of potato (Solanum tuberosum L.): a review. Int J Curr Microbiol Appl Sci 6:489-495

13. Negi P, Jayaprakasha G, Jena B (2003) Antioxidant and antimutagenic activities of pomegranate peel extracts. Food Chem 80:393-397

14. Marco GJ (1968) A rapid method for evaluation of antioxidants. J Am Oil Chem Soc 45:594-598

15. Routray W, Orsat V (2012) Microwave-assisted extraction of flavonoids: a review. Food Bioprocess Tech 5:409-424

16. Khoddami A, Wilkes M, Roberts T (2013) Techniques for analysis of plant phenolic compounds. Molecules 18:2328-2375

17. Reeve R, Hautala E, Weaver M (1969) Anatomy and compositional variation within potatoes. Am Potato J 46:361-373

18. Jin C-Y, Liu H, Xu D, Zeng F-K, Zhao Y-C, Zhang H, Liu G (2018) Glycoalkaloids and phenolic compounds in three commercial potato cultivars grown in Hebei, China. Food Sci Hum Wellness 7:156-162

19. Tierno R, Hornero-Méndez D, Gallardo-Guerrero L, López-Pardo R, de Galarreta JIR (2015) Effect of boiling on the total phenolic, anthocyanin and carotenoid concentrations of potato tubers from selected cultivars and introgressed breeding lines from native potato species. J Food Compos Anal 41:58-65

20. Valcarcel J, Reilly K, Gaffney M, O'Brien NM (2016) Levels of potential bioactive compounds including carotenoids, vitamin $\mathrm{C}$ and phenolic compounds, and expression of their cognate biosynthetic genes vary significantly in different varieties of potato (Solanum tuberosum L.) grown under uniform cultural conditions. J Sci Food Agric 96:1018-1026

21. Zhu X, Cheng Y, Chen P, Peng P, Liu S, Li D, and Ruan R (2016) Effect of alkaline and high-pressure homogenization on the extraction of phenolic acids from potato peels. Innov Food Sci Emerg Technol 37:91-97

22. Mohdaly AAA, Sarhan MA, Mahmoud A, Ramadan MF, Smetanska I (2010) Antioxidant efficacy of potato peels and sugar beet pulp extracts in vegetable oils protection. Food Chem 123:1019-1026

23. Amado IR, Franco D, Sánchez M, Zapata C, Vázquez JA (2014) Optimisation of antioxidant extraction from Solanum tuberosum potato peel waste by surface response methodology. Food Chem 165:290-299

24. Fry SC (1986) Cross-linking of matrix polymers in the growing cell walls of angiosperms. Annu Rev Plant Physiol 37:165-186

25. Ezekiel R, Singh N, Sharma S, Kaur A (2013) Beneficial phytochemicals in potato-a review. Food Res Int 50:487-496

26. Lewis CE, Walker JR, Lancaster JE, Sutton KH (1998) Determination of anthocyanins, flavonoids and phenolic acids in potatoes. I: coloured cultivars of Solanum tuberosum L. J Sci Food Agric 77:45-57

27. Bailey-Serres J, Mittler R (2006) The roles of reactive oxygen species in plant cells. Am Soc Plant Biol 141:311

28. Chun OK, Kim DO, Smith N, Schroeder D, Han JT, Lee CY (2005) Daily consumption of phenolics and total antioxidant capacity from fruit and vegetables in the American diet. J Sci Food Agric 85:1715-1724

29. Floegel A, Kim D-O, Chung S-J, Koo SI, Chun OK (2011) Comparison of ABTS/DPPH assays to measure antioxidant capacity in popular antioxidant-rich US foods. J Food Compos Anal 24:1043-1048

30. Navarre DA, Payyavula RS, Shakya R, Knowles NR, Pillai SS (2013) Changes in potato phenylpropanoid metabolism during tuber development. Plant Physiol Biochem 65:89-101

31. Solfanelli C, Poggi A, Loreti E, Alpi A, Perata P (2006) Sucrose-specific induction of the anthocyanin biosynthetic pathway in Arabidopsis. Plant Physiol 140:637-646 